\title{
Cefonicid Monosodium
}

National Cancer Institute

\section{Source}

National Cancer Institute. Cefonicid Monosodium. NCI Thesaurus. Code C76170.

The monosodium salt form of cefonicid, a second-generation, semi-synthetic, betalactam cephalosporin antibiotic with antibacterial activity. Cefonicid binds to penicillinbinding proteins (PBPs), transpeptidases that are responsible for crosslinking of peptidoglycan. By preventing crosslinking of peptidoglycan, cell wall integrity is lost and cell wall synthesis is halted. 